\title{
Influence of the Mega-Urban Heat Island on Spatial Transfer of Summer Thermal Comfort: Evidence from Tianjin, China
}

\author{
Huanchun HUANG, Yingxia YUN, Hao XU, Ting LIU
}

\begin{abstract}
Human thermal comfort in urban spaces deteriorates as rapid urbanization proceeds. However, effective tests and discoveries of spatial statistic patterns are currently absent. This study collected remote sensing images and measured meteorological data of the summers of 1992-2017, Tianjin of China and aims to clarify patterns of spatial transfer and thermal comfort changes caused by a mega-UHI (Urban Heat Island). An analytic transfer matrix and the spatial autocorrelation were developed to study spatial pattern changes and features of the spatial transfer of thermal comfort caused by UHI. Results show these patterns in the affected areas can be divided into different levels: patterns of low-level affected areas transferred by circular expansion into block-mass jumping, while the position of high-level affected areas remains stable. The spatial transfer of thermal comfort in the affected areas shows two apparent stages: the transfer from areas of high-density and low-storied buildings and into areas of multiple storied buildings, and transfer from areas of low and multiple storied buildings into those of high storied buildings. This implies changes in urban planning can guide spatial, structural, and functional evolution. The study identifies features of spatial change and spatial patterns related to the influence of Mega-UHI on thermal comfort.
\end{abstract}

Keywords: levels of affected areas; spatial autocorrelation; spatial transfer; summer UHI; thermal comfort

\section{INTRODUCTION}

Rapid global urbanization, in recent years, has contributed to continuous urban expansion, leading to frequent urban extreme weather events, especially continuously worsening high temperature and heat-wave hazards in summer [1]. A total of 852 people died in Andhra Pradesh, India, in a $47{ }^{\circ} \mathrm{C}$ heat wave on May 25, 2015. Nearly half of the urban population in China suffered from "charcoal roasting" caused by high temperature in July 2016. On July 26, over 120 sunstroke patients were reported, with 20 of them being critically ill, in Jiangsu Province alone. These incidents are closely related to global warming and high summer temperature as well. However, global air temperature rose only by $0.85{ }^{\circ} \mathrm{C}$ [2] from 1880 to 2012, which cannot explain this phenomenon. Indeed, the above incidents happened only in large cities with rapid urbanization, mainly because global warming and the summer temperature rise are combined with the phenomenon of an urban heat island (UHI) to deteriorate thermal comfort in urban spaces, giving rise to frequent occurrences of incidents harmful to human health. UHI are areas where concentrations of human activity raise ambient temperature levels.

In such rapid urbanization, urban areas swiftly expand and the internal structure of urban land use changes frequently. Artificial landscapes have replaced vegetationintensive natural landscapes, and they are now covered with buildings and hardened pavements [3], resulting in the generation of UHI. Constant changes in land use properties, together with man-made thermal discharge, have brought intensified UHI effects [4]. Changes in radiation and thermal properties such as thermal conductivity, emissivity, reflectivity, and the thermal capacity of urban surfaces cause great variations in surface energy balance. Consequently, urban temperature is higher than those in peripheral rural areas [5]. More importantly, the UHI effect undergoes spatial change and transfer and has a comprehensive spatial influence on human comfort and health.

Under the dual influences of rapid urbanization and global warming [6], UHI has become one of the three major newly recognized problems in urban environmental protection. Summer UHI has the most serious impact on human settlements [7], reducing the thermal comfort of human bodies, and in turn increasing rates of urban violence and leading to a series of social problems $[8,9]$. Enlightened urban planning and construction are two effective responses to the problems of UHI. Therefore, it is necessary to study the comprehensive interaction mechanisms of long-term UHI, thermal comfort, and urban spatial changes.

Tianjin of China, located at $39^{\circ} \mathrm{N}$ and $117^{\circ} \mathrm{E}$, is a global beta second-tier city with a population exceeding 14 million and an urban built-up area totalling $1,156 \mathrm{~km}^{2}$. Tianjin has experienced long-term evolution in the past twenty-five years in a way similar to other world metropolises in urban spaces, especially in the replacement of its primary, secondary, and tertiary industries; urban development from a single center to multiple centers [10]; and major spatial changes in factors such as UHI-related green coverage, building height, building density, hardened pavements, and sky wideness. These changes have given rise to changes in thermal comfort levels at different spatial locations [11]. We selected Tianjin for this study as an example of a megaurban space. By establishing evaluation criteria for the influence of UHI on thermal comfort, this study probes into the spatial transfer patterns and features of the influence of mega-urban heat islands (M-UHI) on thermal comfort. The conclusions provide reasonable support for the optimization and adjustment of urban spatial structures, and for the improvement of microclimatic thermal comfort.

\section{STATE OF THE ART}

Global warming and rapid urbanization make urban thermal environments one of the most theoretically and practically significant research hotspots in the world. "Urban heat island" was taken as the subject for a keyword search for literature in this study. CiteSpace was used to analyze 900 retrieved papers in the "web of science" from 2008 to 2018 . We found that only a few research papers adopted methods and processes with control over the 
sample size, conceptual model, operation mechanism, synchronicity, spatial typicality, weather situation, surface features, and equipment parameters $[12,13]$. The research content concentrated on the phenomena of UHI (UHI intensity, surface temperature, and atmospheric temperature), their causes (urbanization, land use, and greenbelt), and their influence on the climatic environment. Of the 900 papers, 264 involved space and process and 188 related to UHI, but only twelve were related to health and comfort studies (Fig. 1). Existing studies indicate that the occurrence and spatial transfer of UHI are the result of the combined effects of multiple factors $[14,15]$. Changes in urban spatial layout have altered the local general atmospheric circulation, heat absorption, and radiation [16, 17] and led to the spatial transfer of heat islands. Therefore, to clarify spatial transfer features and patterns, a study of the spatial influence of UHI on thermal comfort is needed, which starts from an overall representation of urban spatial transfer and adopts the GIS-RS spatial statistical analysis technique as the analysis method.
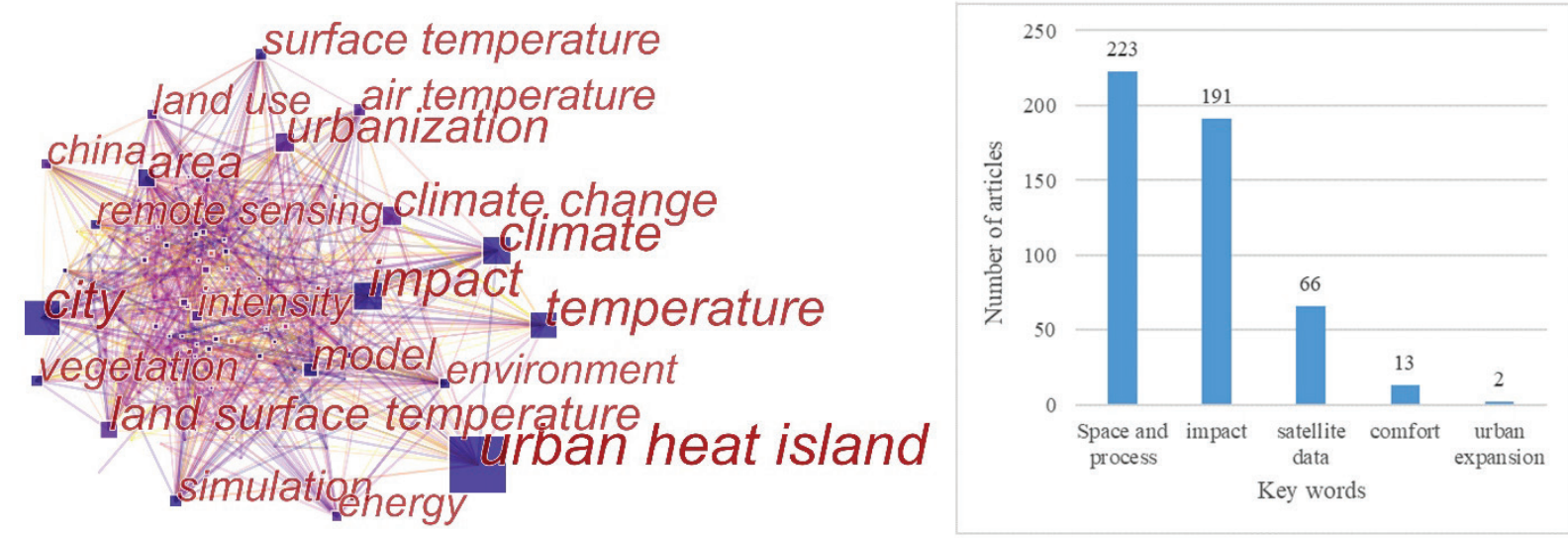

Figure 1 CiteSpace software analysis of research on the UHI effect

To study the intensity of the influence on urban thermal comfort and mutual spatial transfer, it is necessary to undertake surface feature extraction and the inversion of wide-range temperature fields via remote sensing technology. Rao first studied the inversion of urban surface temperature in 1972 using remote satellite sensing images to analyze surface temperature distribution patterns in MidAtlantic coastal cities in America. Rao's research introduced the idea of studying the wide-range urban thermal environment with satellite images [18]. Subsequently, numerous scholars employed remote sensing data to implement studies in various areas. Previous studies extracted land use data using Landsat Thematic Mapper (TM) and Enhanced Thematic Mapper Plus (ETM+) images to study the effects of urban spatial expansion on controlling land surface heat islands $[19,20]$. However, they did not take scientific classification standards into account in the influence on human bodies. A remote sensing study carried out by Kato indicated that highly urbanized regions saved more energy than newly expanded residential areas [21], but this study did not implement a systematic analysis on the spatial transfer of the thermal environment. Existing studies with remote sensing technology concentrated on merely analyzing the temperature fields; few paid attention to the way that different levels of UHI transform internally, or to related studies of influence on urban human comfort and health. Additionally, as to the research methods, the hierarchical classification and standardization on UHI have no touch on the influence on human bodies, the method of spatial correlation analysis, or the effects of spatial proximity [22].

Another approach to studies on the influence of UHI on thermal comfort is the application of the method of surface meteorological measuring stations. A study by Giridharan indicated that atmospheric UHI intensity in high-rise areas of high density reached $1-1.5^{\circ} \mathrm{C}$ [23]. This varied significantly from the test results of typical summer weather in Tianjin conducted by the authors - the highest atmospheric UHI intensity was $5.7{ }^{\circ} \mathrm{C}$ [24], significantly decreasing environmental comfort. Park studied the green space of six blocks in Seoul, reporting that UHI intensity presented a linear relation with $3 \mathrm{D}$ green biomass and that UHI intensity weakens as green biomass increases. However, it is difficult for that study to be elevated to a macro scale of urban space [25]. Jin used twenty-seven monitoring stations to study the relationship between urban morphological parameters and UHI in Singapore within an $8 \mathrm{~km}^{2}$ range, but that study did not involve human comfort [26]. Salata simulated Sapienza University in Rome via the Envi-met model to study urban microclimates. He proposed that urban roof greening and paving improvement could improve thermal comfort during heatwave periods and reduce the health risks of outdoor exposure to people by $60 \%$ [27]. However, with such a limited range, that study could not reflect the way that MUHIs evolve and affect thermal comfort. Radhi used two fixed stations to observe the UHI effects of the humanmade Amwaj Islands in Bahrain. Their study showed that, compared with an uninhabited island, the cooling load of the artificial island increased from $14 \%$ to $26 \%$ [28]. However, there were few observatories in that study, and it cannot explore how the UHI influences the effects of spatial changes in thermal comfort over a wide range. Such studies using surface meteorological stations limited observation data, making it difficult to analyze urban spatial features overall.

Therefore, on the understanding that the observational conditions of meteorological stations must be strictly controlled, this study applied multitemporal remote sensing images and an appropriate spatial statistical model to analyze the trends and features of spatial transfer of MUHI on thermal comfort. The study was carried out from the macroscopic angle of relieving the hazards caused by the UHI on human thermal comfort. The city of Tianjin of 
China was selected as a typical megacity for study which collected twenty-five years of Landsat remote sensing images to conduct an inversion calculation of surface heat island warming. Then, changes were extracted in long-term and multitemporal temperature in both rural areas and urban spaces. The affected areas were divided into thermal comfort zones based on the physiological reaction of human bodies to high-temperatures. In this study, a spatial autocorrelation method was applied to explore the transfer pattern features of spatial influence on summer thermal comfort. From this, it is expected that this study can provide a reasonable reference for urban spatial form planning and layout and offer suggestions for eco-city planning and construction.

The remainder of this study is organized as follows: Section 3 describes the study area and data selection, as well as the temperature inversion and spatial autocorrelation analysis method. Section 4 describes the analysis of the influence of UHI on the spatial transfer of thermal comfort. Section 5 presents the conclusions.

\section{METHODOLOGY \\ 3.1 Overview of the Study Areas}

The study areas selected were the main urban areas in Tianjin, located at $117^{\circ} 13^{\prime} 45^{\prime \prime},-117^{\circ} 18^{\prime} 50^{\prime \prime}, 39^{\circ} 4^{\prime} 25^{\prime \prime}$, and $-39^{\circ} 10^{\prime} 4^{\prime \prime}$ (Fig. 2). According to the typical semi-humid continental monsoon climate, the areas were in monsoon circulation. As the East Asian monsoon prevails, the main climatic characteristics are as follows: four distinct seasons, a hot summer, and a concentrated rainfall. The Pacific subtropical warm-core anticyclone is intensified in the summer half of the year with a prevailing southerly wind, with high air temperature and heavy rainfall. From 2008 to 2017, at 10:30 Beijing time, the average temperature in the Tianjin urban areas was $28.5^{\circ} \mathrm{C}$ in July and August. In the past 20 years, the average temperatures in Tianjin in July and August were $28{ }^{\circ} \mathrm{C}$ and $26.9{ }^{\circ} \mathrm{C}$ respectively, and the monthly average maximum temperatures were $32.38{ }^{\circ} \mathrm{C}$ and $31.38^{\circ} \mathrm{C}$ respectively.

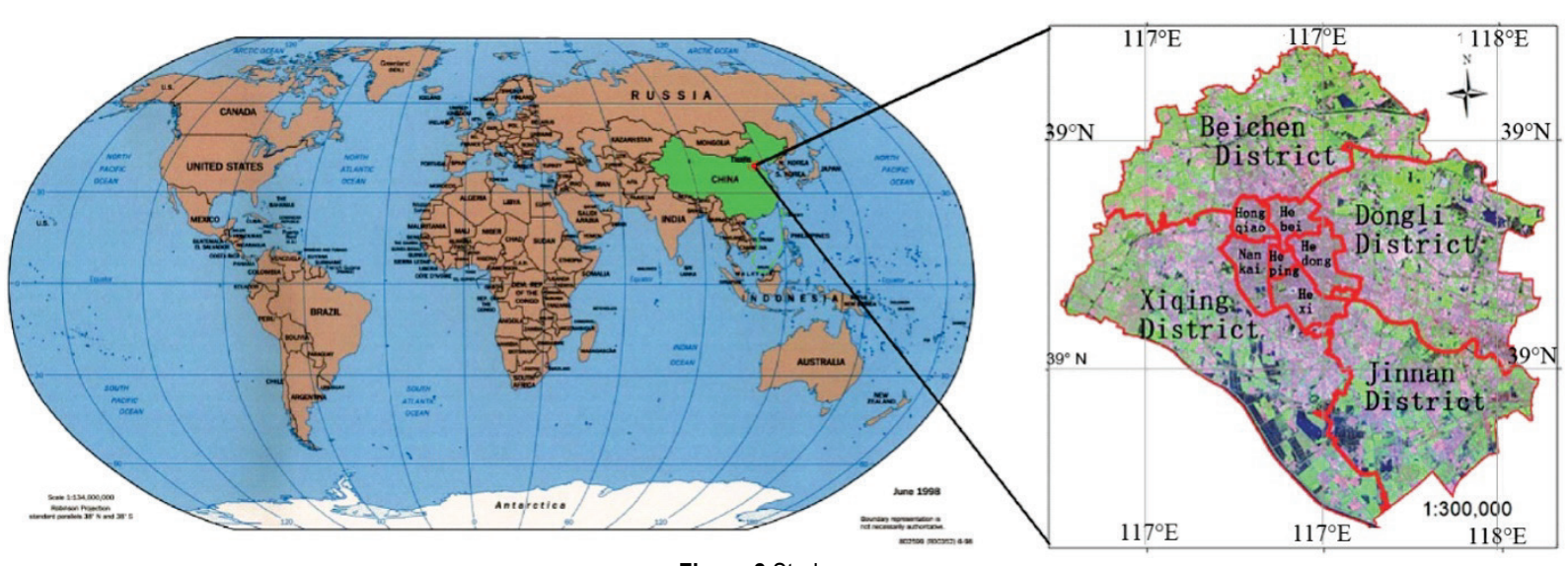

Figure 2 Study area

Tianjin is an important key city in the Asia-Pacific region, one of the four municipalities directly under the central government in China, and a crucial city in the Beijing-Tianjin-Hebei Region - one of three major urban agglomerations in China. In its rapid urbanization, Tianjin has followed a typical pattern of urban spatial expansion. In the past twenty or so years, the area of urban morphology expanded from $280 \mathrm{~km}^{2}$ in 1992 to $1,156 \mathrm{~km}^{2}$, with a three-fold population increase. The study area features high population density and industrial concentration, with many urban buildings renovated in the last twenty-five years. Over time, many multi-storey and high-rise buildings replaced the former low-storied and high-density buildings (one to two stories), and the UHI effect and spatial influence changes generated as a result are typical of similar urban areas.

\subsection{Study Data and Processing}

To generate the original data, Landsat TM 5 and 8 remote sensing images were applied; the spatial resolution was $30 \mathrm{~m}$, and the resolutions of thermal wavebands were $120 \mathrm{~m}$ and $100 \mathrm{~m}$. A satellite passed over the study area at about 10:30, an optimal working hour in the daytime, suitable for studying the influence of the summer UHI on human thermal comfort. According to the features of Tianjin climatic regions over the years, this study selected the hottest period each year-July 7 to August 17. Cloudcoverage ratios of the selected remote sensing images were all at zero; there was no rainfall on the day before the image shooting, and the average wind speed on the shooting day was below $2.35 \mathrm{~m} / \mathrm{s}$.

As the State Council issued a Notice on Several Issues Concerning Real Estate Development in 1992, China ushered in a new period of real estate development and urban renewal and expansion. Since 1992, according to the urban planning and construction history in Tianjin and artificial visual interpretation results of satellite images in urban built-up areas, the spatial evolution underwent three typical stages: 1992-1999, 1999-2006, and 2006 until today. Due to the editing and revision of overall regulations in Tianjin in 2013, the following five representative dates were selected to analyze remote sensing images: July 30, 1992; August 11, 1999; July 21, 2006; July 24, 2013, and July 10, 2017. Furthermore, the study applied graphs in 1992, 1999, 2005, 2013, and 2017, as well as overall planning maps in 1996, 2005, and 2013.

Regard to data preprocessing, firstly, the Tianjin map, urban planning graph, and urban status graph were scanned for an accurate geometric correction within $30 \mathrm{~m}$. Secondly, 
the satellite remote sensing images and registered maps or drawings were uniformly corrected as high-resolution remote sensing images. The unified projection was WGS_1984_UTM_50N, and errors were controlled within $15 \mathrm{~m}$ to guarantee data consistency. Finally, ArcGIS software was used to establish a document database for extraction and statistical analysis.

\subsection{Surface Temperature Inversion Method}

The study applied an image-based algorithm (IB algorithm) that featured simplicity, high accuracy, and easy data acquisition to analyze land surface temperature inversion. As MODIS satellite imaging data in each stage cannot completely cover the study areas, it was not possible to acquire data on atmospheric moisture contents in adjacent periods. Therefore, single-channel and singlewindow algorithms cannot be used for the study areas.

First, radiometric calibration was implemented according to the data manual of NASA and transformed the image element digital number (DN) into corresponding heat radiation intensity. Second, the normalized difference vegetation index (NDVI) and vegetation coverage were calculated. Third, the computing method [29] of emissivity proposed by Zhihao Qin was calculated to calculate land surface emissivity through NDVI and vegetation coverage. Finally, the land surface temperature (LST) was calculated with the following LST computing formula:

$$
L S T=\frac{T}{1+(\lambda T / \rho) \ln \varepsilon}-273.15
$$

where $\lambda$ is the central wavelength of TM6 waveband (11.5 $\mu \mathrm{m}), \quad \rho=h \times \frac{c}{\sigma}=1.438 \times 10^{-2} \mathrm{~K} \quad$ (Stefan-Boltzmann's constant $\sigma=1.38 \times 10^{-23} \mathrm{~J} / \mathrm{K}$, Planck constant $h=$ $6.626 \times 10^{-34} \mathrm{Js}$ and velocity of life $c=2.998 \times 10^{8} \mathrm{~m} / \mathrm{s}$ ).

\subsection{Spatial Autocorrelation Analysis Method}

Spatial autocorrelation analysis is an effective method for studying spatial pattern changes, focusing on analyzing correlations between spatial data, locating singular observed values, and revealing spatial relations between objects and heterogeneous spatial patterns. It can help researchers to understand the progress and prospect of spatial patterns. Moreover, the study of time changes in spatial patterns can reveal relevant driving factors. Two common indices, Getis-Ord $G_{i}^{*}$ and local Moran's I [30, 31 ], were used to analyze the influence of UHI on summer thermal comfort regarding the urban growth process, recognize hotspot regions in thermal comfort changes, and understand the patterns of spatial evolution.

$$
G_{i}^{*}=\frac{\sum_{j=1}^{n} w_{i, j} x_{j}-\frac{\sum_{j=1}^{n} x_{j}}{n} \sum_{j=1}^{n} w_{i, j}}{\sqrt{\frac{\sum_{j=1}^{n} x_{j}^{2}-(\bar{X})^{2}}{n}} \sqrt{\frac{n \sum_{j=1}^{n} w_{i, j}^{2}-\left(\sum_{j=1}^{n} w_{i j}\right)}{n-1}}}
$$

$$
I=\frac{x_{i}-\bar{x}}{\frac{\sum_{j=1, j \neq i}^{n}\left(x_{j}-\bar{x}\right)^{2}}{n-1}-(\bar{x})^{2}} \sum_{j=1, j \neq i}^{n} w_{i, j}\left(x_{j}-\bar{x}\right)^{2}
$$

where $x_{j}$ is the attribute value of element $j ; w_{i j}$ is spatial weight between element $i$ and $j ; n$ is the total number of elements, $\bar{x}$ is the average value of element $x$.

To compute the results of the spatial correlation of Getis-Ord $G_{i}^{*}$ and local Moran's I, a statistical significance test was carried out using z score and p-value, to determine whether there were a spatial agglomeration and a spatial structure. It also certified that some basic spatial processes were exerting effects. For test values in this study, test criteria were taken as $|z|>1.96$, the significance level was $p<0.05$, and the confidence level was $95 \%$.

\section{RESULTS AND DISCUSSION \\ 4.1 UHI Calculation and Affected Degree of Thermal Comfort}

First, TM remote sensing images for the summers of 1992, 1999, 2006, 2013, and 2017 (Fig. 2) were applied for surface temperature inversion with the IB algorithm. The comparison and verification of recording experiments at ten points and fixed meteorological observation stations showed that inversion temperatures of the TM images were all close to actual tested temperatures, and the mean error was $0.38^{\circ} \mathrm{C}$.

Next, the UHI intensity of each point was calculated by ArcGIS software, with this computing formula:

$\Delta T_{\mathrm{ij}}=T_{i j}-\bar{T}_{R}$

where $\Delta T_{i j}$ is the UHI intensity at spatial location $i j ; T_{i j}$ is the surface temperature at spatial location $i j ; \bar{T}_{R}$ is the mean temperature of eighty villages in eight outersuburb directions; and each sampling place is the mean temperature value of this village.

Finally, the influence graph (Fig. 3) of human thermal comfort and health in the summers of 1992, 1999, 2006, 2013, and 2017 were drawn according to the influence grading method in this study. Concerning the computational formula and the classification standard of human thermal comfort degree, "feels-like" temperature, and the human body's feeling about and physiological reaction to high temperatures in adjacent Beijing, the influence of surface UHI on thermal comfort was categorized into five levels (Tab. 1).

The study adopted the formula proposed by Tom and corrected by Bosen for thermal comfort index calculation:

$$
I_{L}=1.8 T+32 \quad 0.55(1 \quad R H)(1.8 T \quad 26)
$$

where $R H$ is the relative humidity (ideal condition: $50 \%$ ); $T$ is the atmospheric temperature $\left({ }^{\circ} \mathrm{F}\right)$; and $I$ is the comfort index. According to Tab. 1, UHI temperature rises affected human thermal comfort and brought about physiological and psychological hazards to human beings. Therefore, it could be said that areas with an increased effect on thermal 
comfort experience deterioration in thermal comfort (the area where thermal comfort is affected by UHI is hereinafter referred to as the affected area).

\begin{tabular}{|c|c|c|c|c|c|c|}
\hline $\begin{array}{l}\text { Affected level of } \\
\text { thermal comfort }\end{array}$ & Zero & Level 1 & Level 2 & Level 3 & Level 4 & Level 5 \\
\hline UHI intensity ${ }^{\circ} \mathrm{C}$ & 0 & $0-2.8$ & $2.8-6.96$ & $6.6-8.9$ & $8.9-11.5$ & Above 11.5 \\
\hline Temperature ${ }^{\circ} \mathrm{C}$ & 28.5 & $28.5-31.3$ & $31.3-35.1$ & $35.1-37.4$ & $37.4-40$ & Above 40 \\
\hline Comfort index & 76.3 & $76.3-80$ & $80-85$ & $85-88$ & $88-91.5$ & Above 91.5 \\
\hline \multirow[t]{2}{*}{$\begin{array}{l}\text { Human thermal } \\
\text { feeling }\end{array}$} & Comfortable & Uncomfortable & $\begin{array}{c}\text { Very } \\
\text { uncomfortable }\end{array}$ & Maladaptive & Very maladaptive & Intolerable \\
\hline & & $\begin{array}{l}\text { Physiological } \\
\text { manifestation is } \\
\text { easy sweating. }\end{array}$ & $\begin{array}{l}\text { Physiological } \\
\text { manifestation is } \\
\text { excessive } \\
\text { sweating. }\end{array}$ & $\begin{array}{l}\text { When Level } 1 \text { early } \\
\text { warning starts, } \\
\text { heartbeats } \\
\text { accelerate, and the } \\
\text { superficial veins } \\
\text { start to expand. }\end{array}$ & $\begin{array}{c}\text { The physiology } \\
\text { gradually starts Levels } 2 \\
\text { and } 3 \text { early warning, } \\
\text { human body perspiration } \\
\text { cannot ensure normal } \\
\text { temperature regulation. }\end{array}$ & $\begin{array}{l}\text { The human body } \\
\text { starts to feel dizzy } \\
\text { and even suffers } \\
\text { from sunstroke and } \\
\text { shock. }\end{array}$ \\
\hline
\end{tabular}
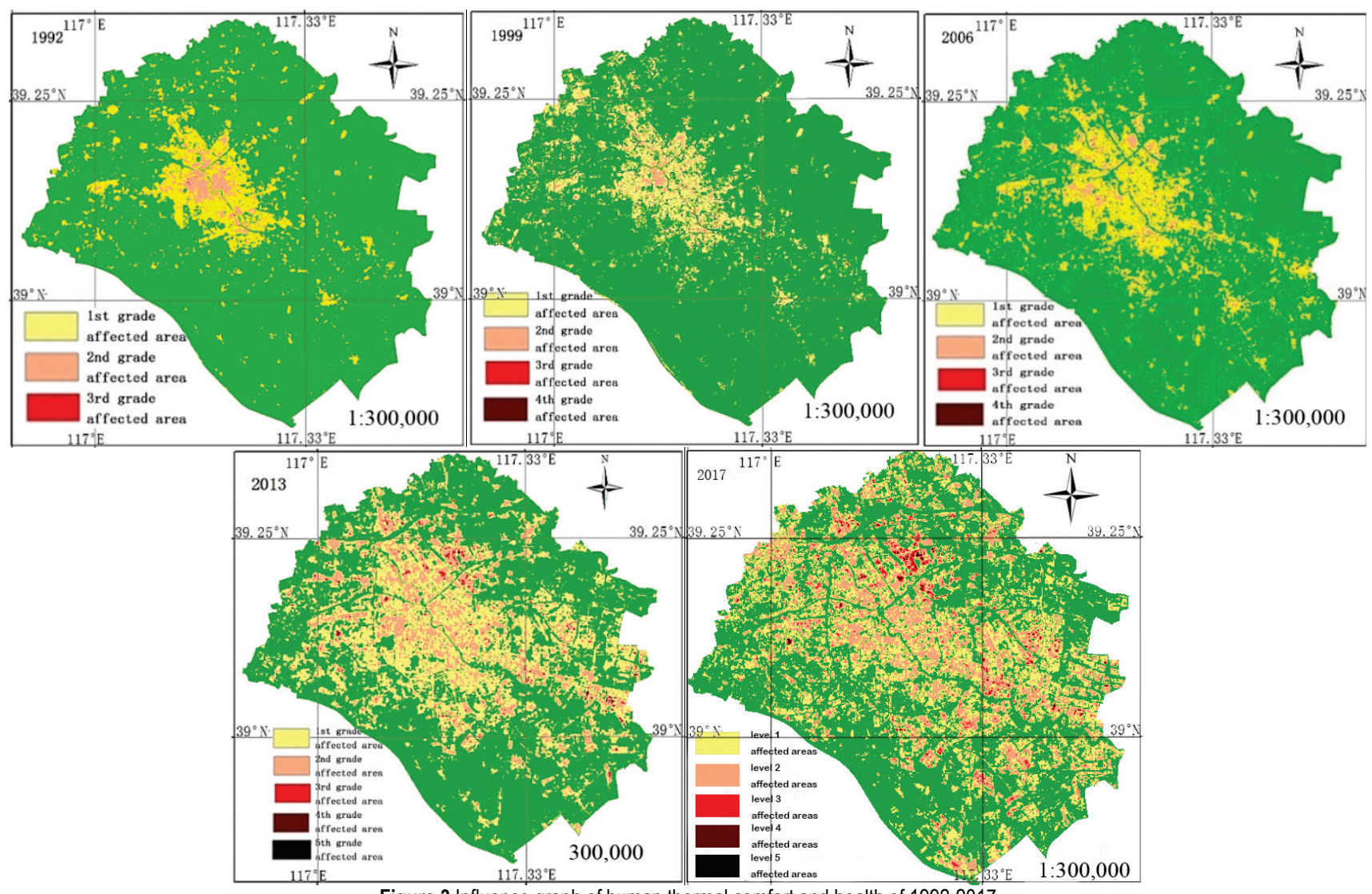

Figure 3 Influence graph of human thermal comfort and health of 1992-2017

Note: the green color indicates the unaffected area

\subsection{Features of Spatial Transfer Changes During 1992-1999}

According to the data from 1992-1999 (Tab. 2), there were $92.573 \mathrm{~km}^{2}$ of deteriorated areas with deteriorating thermal comfort, mainly due to the elevation of Level 1 affected areas. Meanwhile, $90.446 \mathrm{~km}^{2}$ of affected areas had improved; $58.55 \mathrm{~km}^{2}$ were transformed from Level 1 into unaffected areas; $58.64 \%$ of Level 2 affected areas were reduced to below Level 1; and $73.67 \%$ of Level 3 affected areas were reduced to below Level 2. In 1999, there were $0.130 \mathrm{~km}^{2}$ of new Level 4 affected areas, mainly scattered in the suburbs.

Through the analysis of Getis-Ord $G_{i}^{*}$ and local Moran's I indices (Fig. 4), it is found that the number of low-value clusters with temperature decline is greater than that of high-value clusters with temperature rise. High- value clusters grow toward the southeast direction and are mainly distributed at both banks of the Haihe River, and double-port town plaques appear in the north. Communities like Water Park, Style Spring (high-rise), and Water West Garden (a multistoried community) appear in many large low-value clusters. The main reasons are the reconstruction of old cities at both banks of the Haihe River in the urban central segment; two-storied building areas of high-density are demolished; many multistory buildings are built; and ventilating corridors consisting of vegetation, water bodies, and road breaks are added through the spatial pattern of centralized Level 2 affected areas. As a result, areas significantly reduced, indicating that large-area reconstruction of old cities at appropriate locations inside the city could make buildings expand three-dimensionally. In other words, the pattern is transformed from the high- 
density centralization of buildings into moderate dispersal, and vegetation and ventilating corridors are added, thus improving air quality and circulation speed. Finally, the area with an improved thermal environment is bigger than the actual transformed area, generating a general amplification effect.

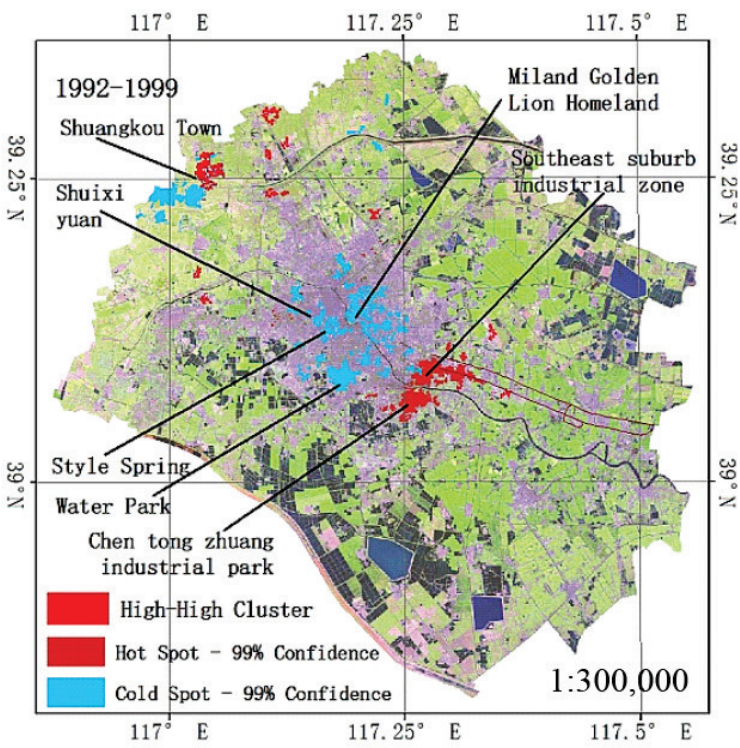

Figure 4 Spatial clustering change of affected areas during 1992-1999

Table 2 Transfer Matrix of Affected Areas, 1992-1999

\begin{tabular}{|c|c|c|c|c|c|c|}
\hline \multirow{2}{*}{ Time } & \multirow{2}{*}{ Levels } & \multicolumn{5}{|c|}{1999} \\
\hline & & Unaffected area & Level 1 & Level 2 & Level 3 & Level4 \\
\hline \multirow{8}{*}{1992} & \multirow{2}{*}{ Unaffected area } & 1739.907 & 75.437 & 2.813 & 0.142 & 0.022 \\
\hline & & $95.69 \%$ & $4.15 \%$ & $0.16 \%$ & $0.01 \%$ & $0.00 \%$ \\
\hline & \multirow{2}{*}{ Level 1} & 58.55 & 131.812 & 13.516 & 0.131 & 0.009 \\
\hline & & $28.7 \%$ & $64.61 \%$ & $6.63 \%$ & $0.06 \%$ & $0.00 \%$ \\
\hline & \multirow{2}{*}{ Level 2} & 5.827 & 25.849 & 21.859 & 0.403 & 0.078 \\
\hline & & $10.79 \%$ & $47.85 \%$ & $40.47 \%$ & $0.75 \%$ & $0.14 \%$ \\
\hline & \multirow{2}{*}{ Level 3} & 0.014 & 0.025 & 0.182 & 0.058 & 0.021 \\
\hline & & $4.67 \%$ & $8.33 \%$ & $60.67 \%$ & $19.33 \%$ & $7.00 \%$ \\
\hline
\end{tabular}

\subsection{Features of Spatial Transfer Change During 1999-2006}

According to the data from 1999-2006 (Tab. 3), affected areas deteriorated mainly because Level 1 affected areas were elevated to Level 2 areas; $66.442 \mathrm{~km}^{2}$ of Level 1 affected areas were newly added and expanded towards outer layers along the central city. $35.15 \mathrm{~km}^{2}$ of Level 2 affected areas were newly added; and the reconstruction of urban spaces improved $46.75 \%$ of the former Level 2 affected areas in the central city. Moreover, the area with the maximum impact continued to reduce and transfer toward the urban periphery, and Level 2 affected areas with industrial concentration in former suburbs tended to expand. Additionally, $0.13 \mathrm{~km}^{2}$ of Level 3 affected areas were newly added, concentrating at the Xiali automobile factory, Tiangang Group, and Yuquan Apartments. A total of $88.89 \%$ of Level 4 affected areas improved, but there were a large number of newly added Level 4 areas, resulting in rather unclear area changes. The newly added areas were mainly located in the suburbs of Tianmu, the Qingjian New Village, and Dasi Town.

Table 3 Transfer Matrix of Affected Areas during 1999-2006

\begin{tabular}{|c|c|c|c|c|c|c|}
\hline \multirow{2}{*}{ Time } & \multirow{2}{*}{ Levels } & \multicolumn{5}{|c|}{2006} \\
\hline & & Unaffected area & Level 1 & Level 2 & Level 3 & Level 4 \\
\hline \multirow{10}{*}{1999} & \multirow{2}{*}{ Unaffected area } & 1647.907 & 147.499 & 12.485 & 0.058 & 0 \\
\hline & & $91.15 \%$ & $8.16 \%$ & $0.69 \%$ & $0.00 \%$ & $0.00 \%$ \\
\hline & \multirow{2}{*}{ Level 1} & 53.078 & 139.824 & 40.363 & 0.0576 & 0 \\
\hline & & $22.75 \%$ & $59.93 \%$ & $17.3 \%$ & $0.03 \%$ & $0.00 \%$ \\
\hline & \multirow{2}{*}{ Level 2} & 5.558 & 12.384 & 20.117 & 0.317 & 0 \\
\hline & & $14.48 \%$ & $32.27 \%$ & $52.42 \%$ & $0.87 \%$ & $0.00 \%$ \\
\hline & \multirow{2}{*}{ Level 3} & 0.043 & 0.0432 & 0.49 & 0.158 & 0 \\
\hline & & $5.88 \%$ & $5.88 \%$ & $66.67 \%$ & $21.57 \%$ & $0.00 \%$ \\
\hline & \multirow{2}{*}{ Level 4} & 0.014 & 0.014 & 0.072 & 0.014 & 0.014 \\
\hline & & $11.11 \%$ & $11.11 \%$ & $55.56 \%$ & $11.11 \%$ & $11.11 \%$ \\
\hline
\end{tabular}

Through an analysis of Getis-Ord $G_{i}^{*}$ and local Moran's I indices during 1999-2006 (Fig. 5), it was found that there were many clustering hotspot areas with reduced thermal comfort, which are mainly distributed along the main urban area and the new coastal area, presenting an expansion trend in the northwest-southeast direction and toward new coastal areas in the southwest suburbs. Affected areas with reduced thermal comfort were concentrated in Dasi Town, Wuxia Town, and the LG electronics factory, forming a small initial cluster with reduced thermal comfort along the Jinbin Road. Most hotspot areas were chiefly industrial areas, like the southeast suburb industrial area, Baimiao industrial area, and Beicang industrial area. Low-value clusters with improved thermal comfort appeared at Gulou and Santiaoshi, where an area of over $4 \mathrm{~km}^{2}$ comprises the 
reconstruction of old urban areas, greatly reducing the influence of UHI in the central city area on thermal comfort, reducing the affected areas substantially.

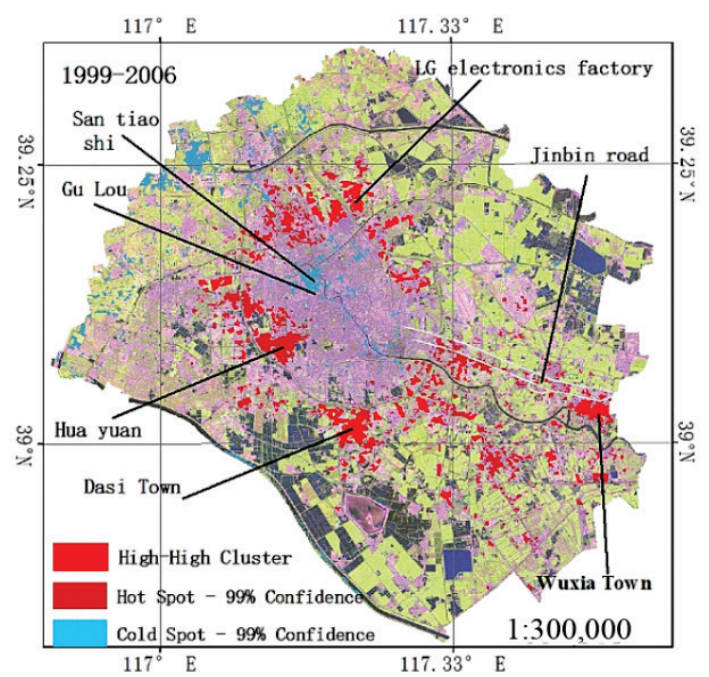

Figure 5Spatial clustering change of affected areas during 1999-2006

\subsection{Features of Spatial Transfer Changes During 2006-2013}

According to the data from 2006 to 2013 (Tab. 4), $433.12 \mathrm{~km}^{2}$ affected areas were newly added, with areas at
Level 2 (and higher) occupying $177.16 \mathrm{~km}^{2}$, mainly because a large number of high-rise and high-density landscapes with a high rate of hardened surfaces appeared in the city; $261.86 \mathrm{~km}^{2}$ of Level 1 affected areas were newly added and continued to expand along the urban periphery, the pattern of which transformed from circular expansion into block-mass jumping; Level 2 affected areas were mainly concentrated toward the southeast spaces; $10.18 \mathrm{~km}^{2}$ Level 3 affected areas were newly added; $50.14 \%$ of the areas were reduced to below Level 2 areas by the end of the period and continued to expand and move toward the eastern spaces; $1.27 \mathrm{~km}^{2}$ of Level 4 affected areas were newly added. $30 \%$ of the areas were lowered to Level 1 at the end of the period and continued to expand and move toward the east also. Level 5 affected areas of $0.08 \mathrm{~km}^{2}$ were newly added. Strongly affected areas appeared in the northeast and remained stable, mainly because many factories were built in this area. The prominent feature in this period was that affected areas of Levels 2 and 3 were improved, primarily because development zones and real estate projects were newly built in the urban periphery. This wide-range construction tends to lead to surface bareness and high summer temperature. Overall, the influence of UHI on thermal comfort gradually reduced, presenting the feature of attenuation over time-green coverage was gradually increasing as the data collection period ended.

\begin{tabular}{|c|c|c|c|c|c|c|c|}
\hline \multirow{2}{*}{ Time } & \multirow{2}{*}{ Levels } & \multicolumn{6}{|c|}{2013} \\
\hline & & Unaffected area & Level 1 & Level 2 & Level 3 & Level 4 & Level 5 \\
\hline \multirow{10}{*}{2006} & \multirow{2}{*}{ Unaffected area } & 1248.242 & 387.21 & 67.445 & 3.008 & 0.3807 & 0.024 \\
\hline & & $73.15 \%$ & $22.69 \%$ & $3.95 \%$ & $0.18 \%$ & $0.02 \%$ & $0.00 \%$ \\
\hline & \multirow{2}{*}{ Level 1} & 22.433 & 157.456 & 117.160 & 2.173 & 0.283 & 0.006 \\
\hline & & $7.49 \%$ & $52.57 \%$ & $39.12 \%$ & $0.73 \%$ & $0.09 \%$ & $0.00 \%$ \\
\hline & \multirow{2}{*}{ Level 2} & 2.502 & 16.582 & 49.014 & 5.5017 & 0.46 & 0.023 \\
\hline & & $3.38 \%$ & $22.38 \%$ & $66.16 \%$ & $7.43 \%$ & $0.62 \%$ & $0.03 \%$ \\
\hline & \multirow{2}{*}{ Level 3} & 0.009 & 0.115 & 0.198 & 0.145 & 0.155 & 0.021 \\
\hline & & $1.40 \%$ & $17.93 \%$ & $30.81 \%$ & $22.55 \%$ & $24.09 \%$ & $3.22 \%$ \\
\hline & \multirow{2}{*}{ Level 4} & 0 & 0.005 & 0 & 0 & 0.013 & 0 \\
\hline & & $0.00 \%$ & $30.00 \%$ & $0.00 \%$ & $0.00 \%$ & $70.00 \%$ & $0.00 \%$ \\
\hline
\end{tabular}

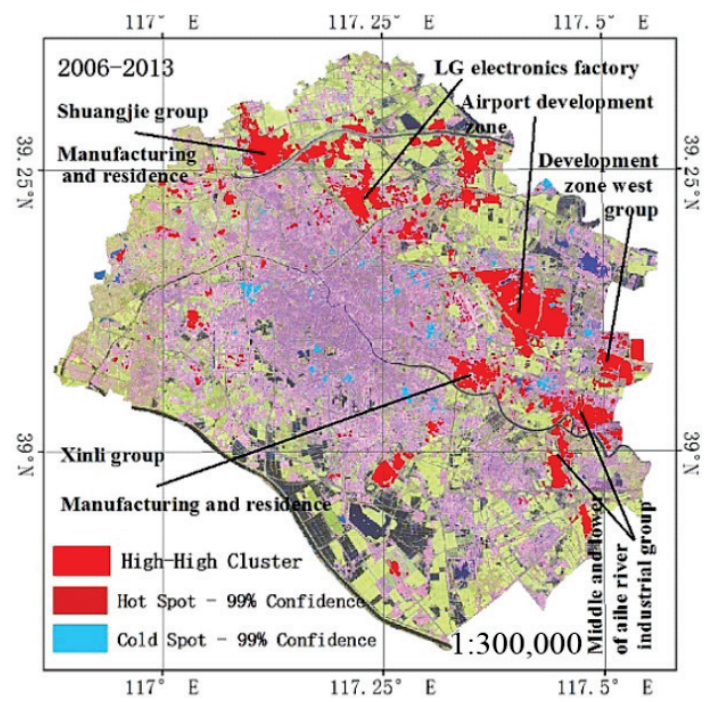

Figure 6 Spatial clustering change of affected areas during 2006-2013

Through the analysis of Getis-Ord $G_{i}^{*}$ and local Moran's I indices (Fig. 6), it is found that hotspot clusters with reduced thermal comfort are mainly in the Konggang development zone, western clusters are in the development zone, a Xinli cluster, industrial clusters on the middle and lower reaches of the Haihe River, and a Shuangjie cluster. The above clusters are mostly industrial, and the suburbs Xinli and Shuangjie clusters double as residential clusters. Many of the low-value clusters are small-scale and can be found at multiple locations inside the old downtown area due to the adjustment of urban functional layout and industrial structures since 2005. These changes have enhanced improved modern service functions such as finance, commerce and trade, science and education, information and tourism, urban life services, ecological environments, and thermal comfort. The 2005-2025 master plan positions urban spatial structure as "one major center and one minor center"; the central city area is the major center, and the new coastal area is the minor or secondary center. In this way, the central zones of two centers developed; therefore, areas with reduced thermal comfort were mainly located in these zones during 2006-2013, expanding linearly toward the east and west on both sides of Jintang Road. Therefore, the adjustment of the functional urban structure and changes in the pattern of urban spatial evolution has been closely related to the 
spatial changes in thermal comfort in the urban environment.

\subsection{Features of Spatial Transfer Changes During 2013-2017}

According to the data during 2013-2017 (Tab. 5), 142.00 $\mathrm{km}^{2}$ of affected areas were newly added; $235.87 \mathrm{~km}^{2}$ of affected areas were improved with an acreage lerthan that of the newly added affected areas; the affected areas were improved, which turned from mainly Level 1 affected areas to affection-free areas; the Level 1 affected areas primarily expanded outward along the cluster centers. Additionally, $72.47 \mathrm{~km}^{2}$ of Level 2 affected areas were newly added; and the growth of Level 2 affected areas in peripheral clusters in the downtown area increased. Level 3 affected areas continued to increase in the Xiaodian cluster and at the LG electronics factory. Affected areas at Levels 4 and 5 showed little improvement, with over $75 \%$ becoming worse.
Through analysis of Getis-Ord $G_{i}^{*}$ and local Moran's I indices (Fig. 7), hotspots were identified with reduced thermal comfort in Dazhangzhuang, Xinnan New City, Konggang New City, and Balitai. These hotspot areas are mainly mixed in function as they are planned for both industrial and residential functions, and the building landscapes primarily present high-rise features. Vegetation bareness is an essential cause of local deterioration of thermal comfort. A large block of warehouses in the Wangwen area was bare of vegetation, increasing the effect of the UHI. Compared with data from 2006-2013, the Shuangjie cluster and the Qingshuang cluster became areas with lowered affected levels. The effects of the UHI in the central city areas were reduced because urban renovation, reconstruction of old residential areas, and vegetation plantation all worked to relieve the UHI effect. Overall, areas with deteriorating thermal comfort have moved toward the south and north sides of the city, indicating that large-scale urban development has been away from the central city area and expanded outward.

Table 5 Transfer Matrix of Affected Areas, 2013-2017

\begin{tabular}{|c|c|c|c|c|c|c|c|}
\hline \multirow{2}{*}{ Time } & \multirow{2}{*}{ Levels } & \multicolumn{6}{|c|}{2017} \\
\hline & & Unaffected area & Level 1 & Level 2 & Level 3 & Level 4 & Level 5 \\
\hline \multirow{12}{*}{2013} & \multirow{2}{*}{ Unaffected area } & 943.625 & 269.884 & 58.706 & 0.88 & 0.089 & 0.002 \\
\hline & & $74.12 \%$ & $21.12 \%$ & $4.61 \%$ & $0.07 \%$ & $0.01 \%$ & $0.00 \%$ \\
\hline & \multirow{2}{*}{ Level 1} & 181.423 & 294.899 & 83.111 & 1.76 & 0.176 & 0.001 \\
\hline & & $32.32 \%$ & $52.53 \%$ & $14.81 \%$ & $0.31 \%$ & $0.03 \%$ & $0.00 \%$ \\
\hline & \multirow{2}{*}{ Level 2} & 5.999 & 45.716 & 162.443 & 18.887 & 0.77 & 0.003 \\
\hline & & $2.57 \%$ & $19.55 \%$ & $69.47 \%$ & $8.08 \%$ & $0.33 \%$ & $0.00 \%$ \\
\hline & \multirow{2}{*}{ Level 3} & 0.138 & 0.286 & 2.005 & 5.365 & 2.93 & 0.104 \\
\hline & & $1.27 \%$ & $2.64 \%$ & $18.52 \%$ & $49.55 \%$ & $27.06 \%$ & $0.96 \%$ \\
\hline & \multirow{2}{*}{ Level 4} & 0.002 & 0.005 & 0.024 & 0.264 & 0.7398 & 0.257 \\
\hline & & $0.14 \%$ & $0.35 \%$ & $1.88 \%$ & $20.43 \%$ & $57.32 \%$ & $19.87 \%$ \\
\hline & \multirow{2}{*}{ Level 5} & 0 & 0 & 0 & 0.001 & 0.01 & 0.064 \\
\hline & & $0.00 \%$ & $0.00 \%$ & $0.00 \%$ & $1.20 \%$ & $13.25 \%$ & $85.54 \%$ \\
\hline
\end{tabular}

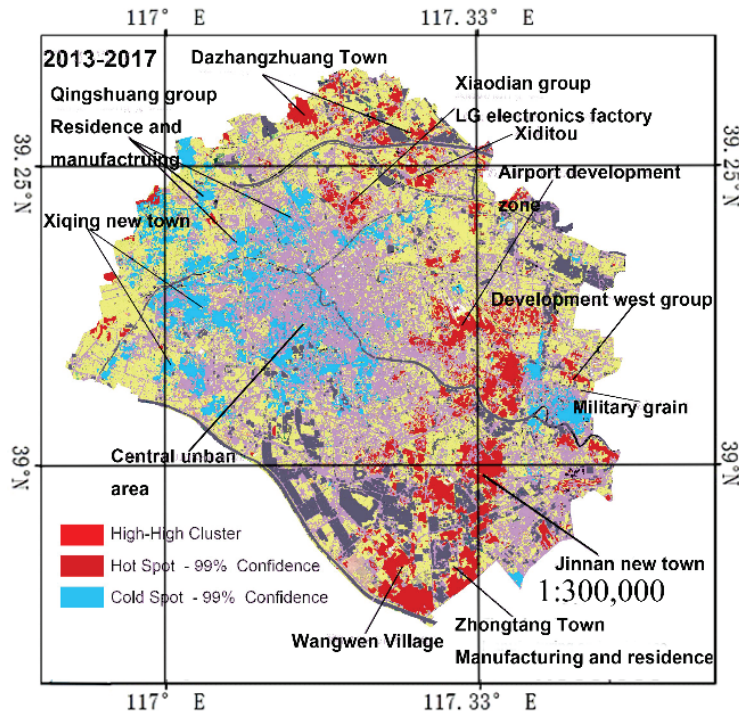

Figure 7 Spatial clustering change of affected areas during 2013-2017

\section{CONCLUSION}

To calculate the features of the spatial transfer in the influence of summer mega-urban UHI on thermal comfort, grading criteria were established for how much UHI influenced thermal comfort in an affected area, based on remote sensing inversion temperatures and measured data from surface meteorological stations over the past twenty- five years. This study applied a transfer matrix and the spatial autocorrelation analysis methods, and reached the following primary conclusions:

(1) In urban expansion, the spatial transfer pattern of the affected areas shows the features of grading differences. High-level, seriously affected areas are fixed, low-level affected areas present great expansion toward the urban periphery, and the expansion pattern is transformed from circular expansion into block-mass jumping.

(2) The spatial transfer of thermal comfort occurs in distinct stages. Mainly affected by the process of replacing major buildings in urban landscapes, this transfer can be divided into two obvious stages: the transformation from low-rise and high-density into multistoried structures, and the transformation from low and multistoried structures into high-rise ones. The first stage improves thermal comfort. The second stage witnesses the gradual deterioration of thermal comfort.

(3) Urban planning is an important driving force affecting the spatial changes that lead to altering thermal comfort, and affects changes in urban spatial structure and construction intensity. Our results suggest that urban planning in this area has further affected UHI intensity and spatial transfer by guiding industries and land use layout, which has then given rise to corresponding spatial transfer in areas where thermal comfort is affected.

The spatial-temporal transfer features and the patterns of the influence of M-UHI on thermal comfort are made 
clear in this study. It provides a useful research basis for the evaluation of the microclimatic influences of urban spatial structural planning and overall urban land use layout. Furthermore, this study offers a certain scientific basis for weakening UHI and evaluating their influence on thermal comfort. Therefore, this study is of great importance to the improvement of comfort, health, and the safety of urban human settlements.

This study was based on Landsat TM satellite images, but the spatial resolution $(30 \mathrm{~m})$ was not precise enough to depict fine changes in local areas, as it lacked appropriate simulation and prediction studies on spatial changes. In the future, a fine spatial study of the UHI influence on human thermal comfort will be carried out to lay a stronger foundation for establishing a prediction model for future trends, proposing accurate and effective planning and reconstruction suggestions for the research areas.

\section{Acknowledgments}

This study was supported by grants from the National Natural Science Foundation of China (NSFC) project (31600571), the Top-notch Academic Programs Project of Jiangsu (PPZY2015A063).

\section{REFERENCES}

[1] Méndez-Lázaro, P. A., Pérez-Cardona, C. M., Rodríguez E., Martínez, O., Taboas, M., Bocanegra, A., \& Mendez-Tejeda, R. (2016). Climate change, heat, and mortality in the tropical urban area of San Juan, Puerto Rico. International Journal of Biometeorology, 62 (5), 1-9.

[2] Stocker, T. F., Qin, D., Plattner, G. K., Tignor, M., Allen, S. K., Boschung, J... \& Midgley, P. M. (2013). Contribution of working group 1 to the fifth assessment report of the intergovernmental panel on climate change. Climate change 2013: The physical science basis. Cambridge, UK: Cambridge University Press.

[3] Yao R., Wang, L., Huang, X., Niu, Z., Liu, F., \& Wang, Q. (2017). Temporal trends of surface urban Heat Island and associated determinants in major Chinese cities. Science of the Total Environment, 609, 742-754. https://doi.org/10.1016/j.scitotenv.2017.07.217

[4] Li, G., Zhang, J., Cheng, H., Zhao, L., \& Tian, H. (2012). Urban heat island effect against the background of global warming and urbanization. Advances in Meteorological Science and Technology, 2(6), 45-49.

[5] Chen, X., \& Jeong, S. (2018). Shifting the urban heat island clock in a megacity: a case study of Hong Kong. Environmental Research Letters, 13(1), 014014. https://doi.org/10.1088/1748-9326/aa95fb

[6] Crowley, T. J. (2000). Causes of climate change over past 1000 years. Science, 289(5477), 270-277. https://doi.org/10.1126/science.289.5477.270

[7] Canyon, D. V., Burkle, F. M., \& Speare, R. (2015). Managing community resilience to climate extremes, rapid unsustainable urbanization, emergencies of scarcity, and biodiversity crises by use of a disaster risk reduction bank. Disaster Medicine and Public Health Preparedness, 9(6), 619-624. https://doi.org/10.1017/dmp.2015.124

[8] Bennett, J. E., Blangiardo, M., Fecht, D., Elliott, P., \&Ezzati, M. (2014). Vulnerability to the mortality effects of warm temperature in the districts of England and Wales. Nature Climate Change, 4(4), 269-273. https://doi.org/10.1038/nclimate2123

[9] Wong, L. P., Alias, H., Aghamohammadi, N., Aghazadeh, S., \& Sulaiman, N. M. N. (2017). Urban heat island experience, control measures and health impact: a survey among working community in the city of Kuala Lumpur. Sustainable Cities and Society, 35, 660-668. https://doi.org/10.1016/j.scs.2017.09.026

[10] Wen, H. \& Tao, Y. (2015). Polycentric urban structure and housing price in the transitional China: Evidence from Hangzhou. Habitat International, 46, 138-146. https://doi.org/10.1016/j.habitatint.2014.11.006

[11] Stewart, I. D., Oke, T. R., \& Krayenhoff, E. S. (2014). Evaluation of the "local climate zone" scheme using temperature observations and model simulations. International Journal of Climatology, 34(4), 1062-1080. https://doi.org/10.1002/joc.3746

[12] Stewart, I. D. (2011). A systematic review and scientific critique of methodology in modern urban heat island literature. International Journal of Climatology, 31(2), 200217. https://doi.org/10.1002/joc.2141

[13] Leal Filho, W., Icaza, L. E., Neht, A., Klavins, M., \& Morgan, E. A. (2018). Coping with the impacts of urban heat islands. A literature-based study on understanding urban heat vulnerability and the need for resilience in cities in a global climate change context. Journal of Cleaner Production, 171, 1140-1149. https://doi.org/10.1016/j.jclepro.2017.10.086

[14] Phelan, P. E., Kaloush, K., Miner, M., Golden, J., Phelan, B., Silva III, H., \& Taylor, R. A. (2015). Urban heat islands: mechanisms, implications, and possible remedies. Annual Review of Environment and Resources, 40, 285-307. https://doi.org/10.1146/annurev-environ-102014-021155

[15] Leal Filho, W., Icaza, L. E., Emanche, V. O., \& Quasem AlAmin, A. (2017). An evidence-based review of impacts, strategies and tools to mitigate urban heat islands. International Journal of Environmental Research and Public Health, 14(12), 1600. https://doi.org/10.3390/ijerph14121600

[16] Oke, T. R. (1981). Canyon geometry and the nocturnal urban heat island: Comparison of scale model and field observations. Journal of Climatology, 1(3), 237-254 https://doi.org/10.1002/joc.3370010304

[17] Deilami, K., Kamruzzaman, M., \& Liu, Y. (2018). Urban heat island effect: A systematic review of spatio-temporal factors, data, methods, and mitigation measures. International Journal of Applied Earth Observation and Geoinformation, 67, 30-42. https://doi.org/10.1016/j.jag.2017.12.009

[18] Rao, P. K. (1972). The remote sensing of urban heat island from an environmental satellite. Bulletin of the American Meteorological Society, 53(7), 647-648.

[19] Kim, J., Lee, D., Sung, S., Jeong, S., \& Park, J. (2015). Study of vulnerable district characteristics on urban heat island according to land use using normalized index. Journal of Korea Planning Association, 50(5), 59-72. https://doi.org/10.17208/jkpa.2015.08.50.5.59

[20] Yusuf, Y. A., Pradhan, B., \& Idrees, M. O. (2014). Spatiotemporal assessment of urban heat island effects in Kuala Lumpur metropolitan city using Landsat images. Journal of the Indian Society of Remote Sensing, 42(4), 829-837. https://doi.org/10.1007/s12524-013-0342-8

[21] Kato, S. \& Yamaguchi, Y. (2007). Estimation of storage heat flux in an urban area using ASTER data. Remote Sensing of Environment, 110(1), 1-17. https://doi.org/10.1016/j.rse.2007.02.011

[22] Chun, B. \& Guldmann, J. M. (2014). Spatial statistical analysis and simulation of the urban heat island in highdensity central cities. Landscape and Urban Planning, 125, 76-88. https://doi.org/10.1016/j.landurbplan.2014.01.016

[23] Giridharan, R., Ganesan, S., \& Lau, S. S. Y. (2004). Daytime urban heat island effect in high-rise and high-density residential developments in Hong Kong. Energy and Buildings, 36(6), 525-534. https://doi.org/10.1016/j.enbuild.2003.12.016 
[24] Huang, H. C. (2014). A study of the mechanism of the urban heat island formation, evolution and planning strategies. Doctoral dissertation of Tianjin University. Online at https://www.globethesis.com/?t=1221330452970 592.

[25] Park, J., Kim, J. H., Lee, D. K., Park, C. Y., \& Jeong. S. G. (2017). The influence of small green space type and structure at the street level on urban heat island mitigation. Urban Forestry \& Urban Greening, 21, 203-212. https://doi.org/10.1016/j.ufug.2016.12.005

[26] Jin, H., Cui, P., Wong, N. H., \& Ignatius, M. (2018). Assessing the effects of urban morphology parameters on microclimate in Singapore to control the urban heat island effect. Sustainability, 10(1), 206. https://doi.org/10.3390/su10010206

[27] Salata, F., Golasi, I., Petitti, D., de Lieto Vollaro, E., Coppi, M., \& de Lieto Lieto Vollaro, A. (2107). Relating microclimate, human thermal comfort and health during heat waves: an analysis of heat island mitigation strategies through a case study in an urban outdoor environment. Sustainable Cities and Society, 30, 79-96. https://doi.org/10.1016/j.scs.2017.01.006

[28] Radhi, H., Sharples, S., \& Assam, E. (2015). Impact of urban heat island on the thermal comfort and cooling energy demand of artificial islands - a case study of AMWAJ Islands in Bahrain. Sustainable Cities and Society, 19, 310318. https://doi.org/10.1016/j.scs.2015.07.017

[29] Qin, Z. H., Li, W. J., Xu, B., Cheng, Z. X., \& Liu, J. (2004). The estimation of land surface emissivity for Landsat TM6. Remote Sensing for Land and Resources, 17(3), 28-42.

[30] Mohan, M., Kikegawa, Y., Gurjar, B. R., Bhati, S., \& Kolli, N. R. (2013). Assessment of urban heat island effect for different land use-land cover from micrometeorological measurements and remote sensing data for megacity Delhi. Theoretical and Applied Climatology, 112(5), 647-658. https://doi.org/10.1007/s00704-012-0758-z

[31] Getis, A. (2015). Spatial association, measures of. International Encyclopedia of the Social \&Behavioral Sciences (Second Edition), 100-104. https://doi.org/10.1016/B978-0-08-097086-8.72055-1

[32] Fang, X., Li, L., Du, W., Dang, B., Cheng, C., \& Shu, W. (2015). Comparative analysis of urban and rural climate comfortabilities in Beijing in past 30 years. Meteorological Science and Technology, 43(5), 918-924.

\section{Contact information:}

Huanchun HUANG, PhD, Associate Professor

College of Landscape Architecture, Nanjing Forestry University,

No. 159 Lonpan Road, Nanjing, 210037, Jiangsu, P. R. China

E-mail: huangyanlin2010@163.com

Yingxia YUN, PhD, Professor

(Corresponding author)

School of Architecture, Tianjin University,

No. 92 Weijin Road, Nankai District, 300072, Tianjin, P. R. China

E-mail: yunyx@126.com

Hao XU, PhD, Professor

(Corresponding author)

College of Landscape Architecture, Nanjing Forestry University,

No. 159 Lonpan Road, Nanjing, 210037, Jiangsu, P. R. China

E-mail: 248186055@qq.com

Ting LIU, Master

Faculty of Architecture, Design and Planning, the University of Sydney,

456P+HW Camperdown, Sydney, Australia

Email: tliu3372@uni.sydney.edu.au 